\title{
Speciation, Dissolution, and Redox Reactions of Chromium Relevant to Pretreatment and Separation of High-Level Tank Wastes
}

(Project Number: 81896)

\section{Principal Investigator}

Dhanpat Rai

Pacific Northwest National Laboratory

P.O. Box 999, MSIN P7-50

Richland, WA 99352

509-373-5988 (phone)

509-372-1632(fax)

mailto:dhan.rai@pnl.gov

\section{Co-Investigators}

Linfeng Rao

Lawrence Berkeley National Laboratory

1 Cyclotron Road Mailstop 70A-1150

Berkeley, CA 94720

510-486-5427 (phone)

510-486-5596 (fax)

LRao@1bl.gov

Sue B. Clark

Department of Chemistry

Washington State University

Fulmer 317 A

Pullman, WA

s_clark@wsu.edu 


\section{Research Objectives}

This proposed research builds on the fundamental data developed under former EMSP project (65368) and seeks to develop additional fundamental data for chromium $(\mathrm{Cr})$ reactions that are not currently available but are essential for the processing of high-level waste (HLW). Our objectives are to study 1) the dissolution of several solid phases (e.g., $\mathrm{CrOOH}, \mathrm{Cr}_{2} \mathrm{O}_{3}$ (c), and $\mathrm{Fe}$ and $\mathrm{Cr}$, binary hydroxides, identified to be important from sludge leaching studies) in highly alkaline solutions and in the presence of other electrolytes (e.g., carbonate, phosphate, sulfate, nitrite), and 2) the effect of the nature of $\mathrm{Cr}$ solid phases and aqueous species on their redox reactivity with a variety of potential oxidants (e.g., $\mathrm{O}_{2}$ and ferrate). This information will provide critical support for developing enhanced pretreatment strategies for removing $\mathrm{Cr}$ from HLW and will achieve a major cost reduction in HLW disposal.

Thermodynamic and kinetic data concerning the behavior of $\mathrm{Cr}$ in multi-component, highly nonideal electrolyte systems will be obtained. A model describing such behavior will be developed based on these fundamental data, tested with actual HLW tank sludge washing, and incorporated into the Environmental Simulations Program (ESP) model for use by Hanford, Savannah River, and other U. S. Department of Energy (DOE) site personnel for predicting the efficacy of enhanced pretreatment strategies for the removal of Cr from HLW.

\section{Research Progress and Implications}

Prior to the research performed under our current EMSP project, little information was available on the solubility, speciation, or redox reactivity of $\mathrm{Cr}$ (III) in tank-like environments.

Consequently, the behavior of $\mathrm{Cr}$, including dissolution and redox, in the proposed sludge washing processes (caustic leaching or oxidative leaching) was not understood, nor could it be predicted.

Our research thus far has consisted of three major components: 1) characterization of $\mathrm{Cr}$ species in solutions from acidic to highly alkaline, 2) determination and modeling of the solubility of $\mathrm{Cr}(\mathrm{OH})_{3}(\mathrm{~s})$ in highly alkaline and concentrated/mixed electrolyte solutions, and 3) study of the oxidation of $\mathrm{Cr}(\mathrm{III})$ by $\mathrm{H}_{2} \mathrm{O}_{2}$ and persulfate in alkaline solutions. To enhance the application of our results to "real-world" problems, we compared and tested our results with those from actual tank sludge washing supported by the Tanks Focus Area (TFA). Accomplishments under this EMSP project have been communicated in detail in the forms of journal articles, national conference presentations, and regular technical progress reports. The following are brief summaries and highlights. 


\section{Speciation of $\mathrm{Cr}(\mathrm{III})$ in Acidic to Strongly Alkaline Solutions}

Chromatographic Separation of Cr(III) Oligomers. Several methods have been developed to isolate macro amounts of $\mathrm{Cr}$ (III) oligomers using chromatographic techniques. This allows us to investigate the chemical structures (i.e., speciation) of the separated fractions and to study the oxidation of isolated oligomers. The effect of solution $\mathrm{pH}$ was evaluated by conducting the separations with $\mathrm{Cr}$ solutions under different conditions. A capillary electrophoresis approach was also developed to separate minor quantities of the oligomers and to verify the resolution and separation of chromatography [Rao et al. 2002; Friese et al. 2002a].

Characterization of $\mathbf{C r}$ (III) species. The separated $\mathrm{Cr}$ (III) species were characterized by a variety of methods, including UV-VIS, X-ray absorption spectroscopy (EXAFS), and capillary electrophoresis (CE). Selected results are presented below.

The UV-VIS absorption spectra of the solutions containing the separated $\mathrm{Cr}$ (III) species (separated by ion exchange) are shown in Figure 1. The energy shift (toward longer wavelength) and the intensity enhancement of the absorption bands, from the monomer through dimer, trimer, and tetramer, to the aged/unseparated solution are interpreted in the context of the structures of the $\mathrm{Cr}$ (III) species and the ligand field theory.

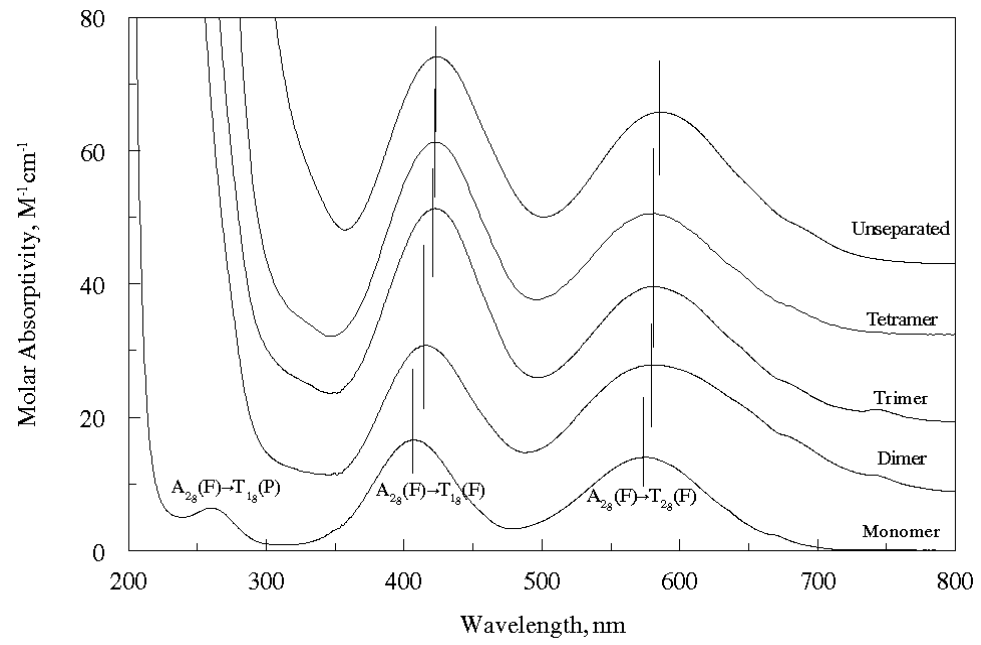

Figure 1. UV/Vis absorption spectra of $\mathrm{Cr}(\mathrm{III})$ monomer, dimer, trimer, tetramer and unseparated $\mathrm{Cr}$ (III) solutions. The spectra are shifted along y-axis for better viewing.

The UV-VIS absorption bands of the Cr(III) oligomers are quite broad. Consequently, absorption maxima of the separated fractions alone do not guarantee that a single Cr(III) species has been isolated. Yet, isolation of single species is important for resolving EXAFS spectra and for our oxidation studies. Therefore, we have used CE as an additional "quality assurance 
check" and have verified the purity of our isolated fractions of $\mathrm{Cr}(\mathrm{III})$ oligomers.

Chromatograms of $\mathrm{Cr}$ solutions indicate that the charge density of the oligomers increases with the degree of polymerization [Friese et al. 2002a].

Figure 2 shows the Fourier transforms of the EXAFS spectra of a few $\mathrm{Cr}$ (III) solution samples. Figure 2a shows the results for the separated monomer in the solution and on the ion exchange resin. The best fit indicates that there are six oxygens around the $\mathrm{Cr}$ at $1.97 \AA$, but no $\mathrm{Cr}$ at $3 \AA$, confirming the monomeric nature of this $\mathrm{Cr}$ (III) species. Figure $2 \mathrm{~b}$ indicates that the separated $\mathrm{Cr}$ (III) dimer, both in solution and on the resin, have one $\mathrm{Cr}$ at $2.97 \AA$, confirming the dimeric nature of this species.

Figure 2c shows the effect of alkalinity on the oligomerization of $\mathrm{Cr}$ (III) in solutions from acidic to highly alkaline. All of the spectra show an oxygen shell (6 oxygen atoms) at around $1.99 \AA$. All but the spectra for the solution with $\mathrm{pH} 2$, illustrate the feature $(\sim 2.99 \AA)$ that results from $\mathrm{Cr}-\mathrm{Cr}$ scattering. The intensity of the $\mathrm{Cr}-\mathrm{Cr}$ scattering increases as the alkalinity is increased. This demonstrates that the oligomerization of $\mathrm{Cr}$ (III) is facilitated by higher alkalinity. Such effect has significant impact on the solubility of $\mathrm{Cr}(\mathrm{III})$ in alkaline solutions, which is described in subsequent discussions on solubility.
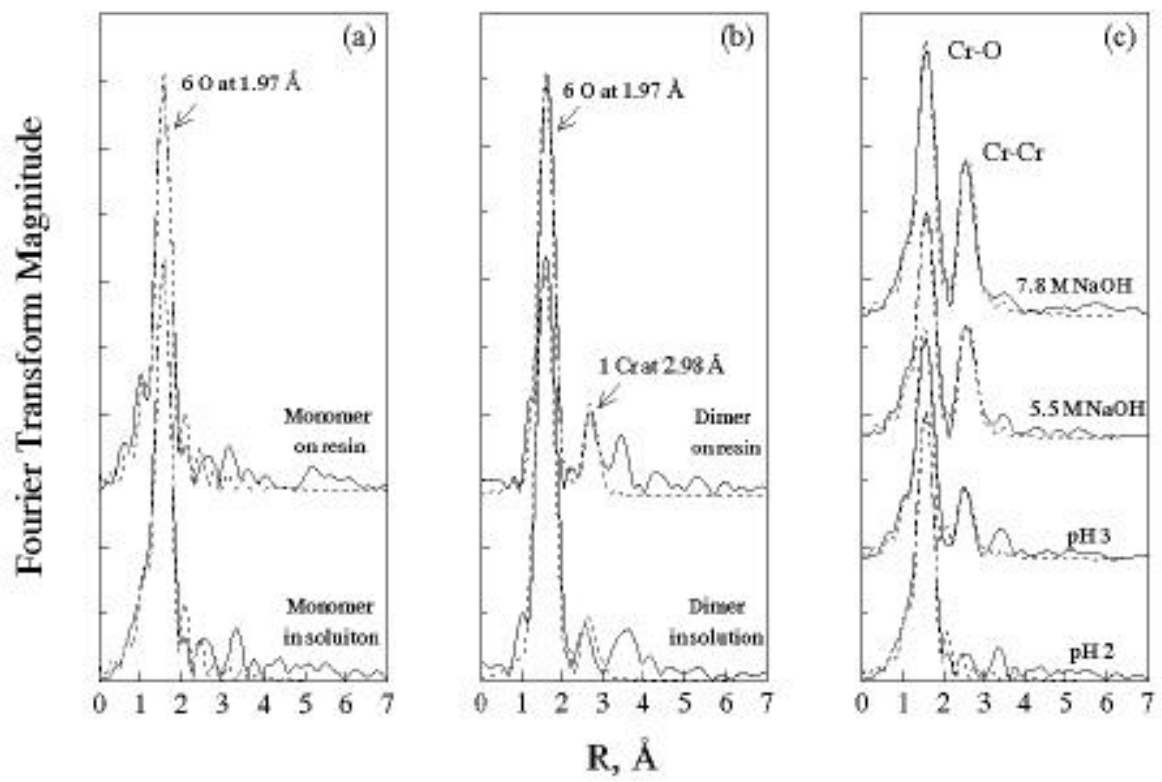

Figure 2. The Fourier transforms of the EXAFS spectra of $\mathrm{Cr}$ (III) solutions. Monomer in solution and on resin (a); dimer in solution and on resin (b), and $\mathrm{Cr}(\mathrm{III})$ solutions of different alkalinity (c). Solid line: experimental; dashed line: fit. 


\section{Impact of Speciation, lonic Strength, and Mixed Electrolytes on Solubility: Solubility of $\mathrm{Cr}(\mathrm{OH})_{3}(\mathrm{am})$ in Strongly Alkaline Solutions}

The solubility of $\mathrm{Cr}(\mathrm{OH})_{3}(\mathrm{am})$ was measured in $\mathrm{NaOH}(0.003$ to $10.5 \mathrm{~m})$ and mixed/concentrated $\mathrm{NaOH} / \mathrm{NaNO}_{3}$ solutions at $22 \pm 2^{\circ} \mathrm{C}$ [Rai et al. 2002]. A combination of techniques, X-ray absorption spectroscopy (XAS) and stripping analyses, was used to identify aqueous species and to confirm that the soluble $\mathrm{Cr}$ was present as $\mathrm{Cr}(\mathrm{III})$.

The aqueous $\mathrm{Cr}$ concentrations in equilibrium with $\mathrm{Cr}(\mathrm{OH})_{3}(\mathrm{am})$ increase dramatically with an increase in $\mathrm{NaOH}$ concentrations (Figure 3). Based on the findings in our speciation studies and the thermodynamic analyses of the data, we could model this observed solubility behavior by invoking two dominant $\mathrm{Cr}(\mathrm{III})$ species, $\mathrm{Cr}(\mathrm{OH})_{4}{ }^{-}$and $\mathrm{Cr}_{2} \mathrm{O}_{2}(\mathrm{OH})_{4}{ }^{2-}$, and by including Pitzer ioninteraction parameters for $\mathrm{Na}^{+}-\mathrm{Cr}(\mathrm{OH})_{4}{ }_{4}^{-}$and $\mathrm{Na}^{+}-\mathrm{Cr}_{2} \mathrm{O}_{2}(\mathrm{OH})_{4}{ }^{2-}$. As shown in Figure 3, the model prediction satisfactorily describes the observed solubility.
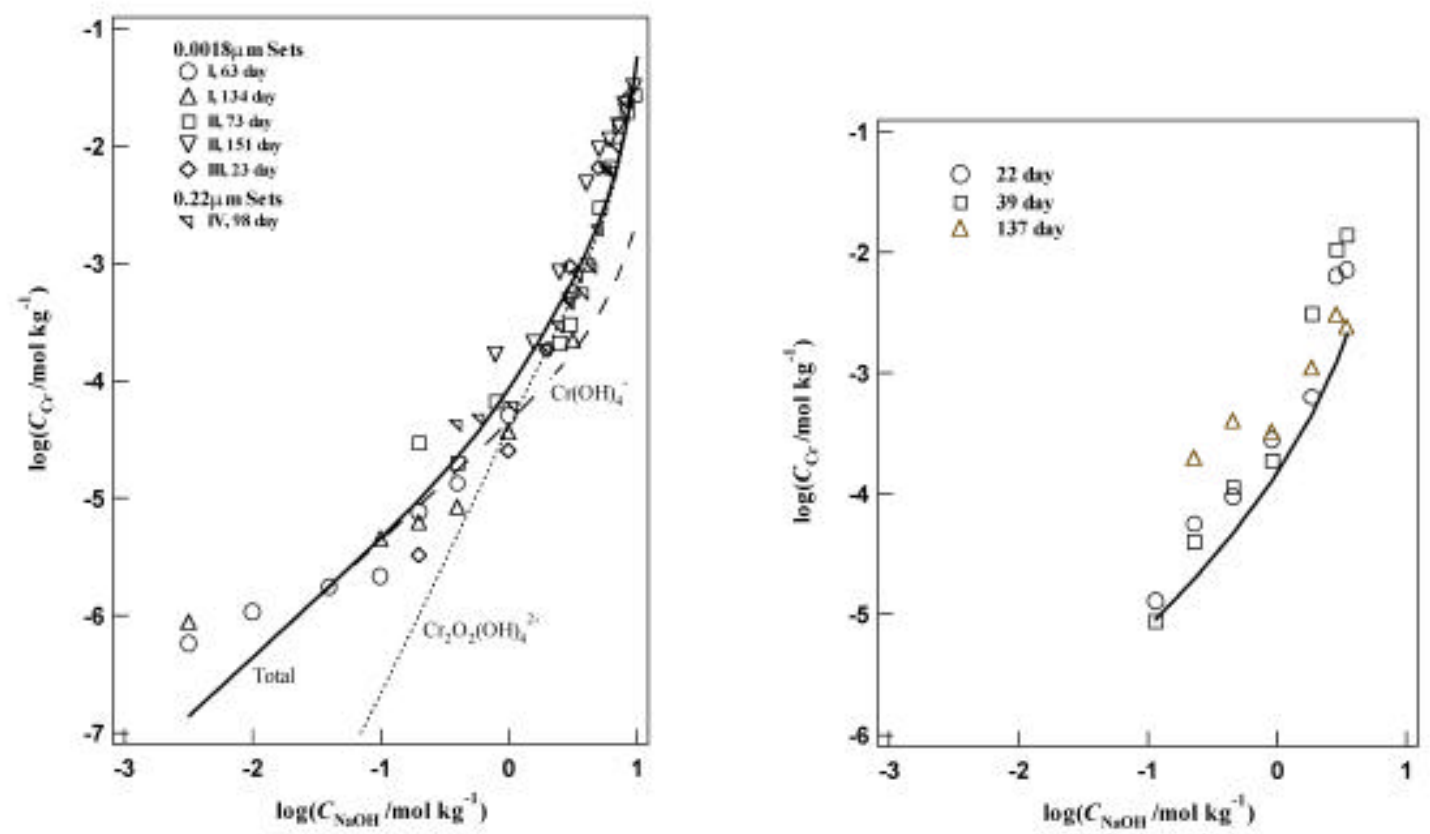

Figure 3. Aqueous chromium concentrations from $\mathrm{Cr}(\mathrm{OH})_{3}(\mathrm{am})$ suspensions in $\mathrm{NaOH}$ (left) and in $4.6 \mathrm{~m} \mathrm{NaNO}_{3}$ containing different concentrations of $\mathrm{NaOH}$ (right). Lines represent predicted concentrations using the thermodynamic data reported in Rai et al. [2001]. Solid line represents total chromium concentrations; other lines represent concentrations of different species as marked in the figure. 
This model was further tested using the experimental $\mathrm{Cr}(\mathrm{OH})_{3}(\mathrm{am})$ solubility in mixed $\mathrm{NaOH}$ and $\mathrm{NaNO}_{3}$ solutions. The $\mathrm{Cr}$ concentrations predicted by the model were in reasonably close agreement with the observed concentrations in mixed $\mathrm{NaOH}-\mathrm{NaNO}_{3}$ solutions (Figure 3). The thermodynamic parameters for the dissolution of $\mathrm{Cr}(\mathrm{OH})_{3}(\mathrm{am})$ in these systems, along with the ion interaction parameters, are provided in detail in Rai et al. [2002].

\section{Impact of Speciation on Redox: Oxidation of $\mathrm{Cr}(\mathrm{III})$ by Peroxide and Persulfate}

Two oxidants were studied, peroxide $\left(\mathrm{H}_{2} \mathrm{O}_{2}\right)$ and the persulfate anion $\left(\mathrm{S}_{2} \mathrm{O}_{8}{ }^{-}\right)$. Peroxide is of interest because of its favorable reduction potential relative to $\mathrm{Cr}$ (III) oxidation to chromate, and because its use does not add unwanted components to the already complex waste stream. Persulfate is of interest because of work completed by Russian scientists on its oxidation of $\mathrm{Cr}(\mathrm{III})$ in alkaline systems. Krot et al. [1999] indicated that persulfate may be preferred over peroxide and other common oxidants because of its reactivity towards $\mathrm{Cr}$ (III) and because it could be applied such that little increase in waste volume occurred. However, for both hydrogen peroxide and persulfate, no mechanistic data were available prior to our work under this EMSP project.

Oxidation of $\mathrm{Cr}$ (III) by $\mathrm{H}_{2} \mathrm{O}_{2}$ in Alkaline Solutions. The oxidation of $\mathrm{Cr}(\mathrm{III})$ was followed by monitoring the increase of absorbance of $\mathrm{Cr}(\mathrm{VI})$ at $372 \mathrm{~nm}$. The oxidation was found to be the first order with respect to the concentrations of $\mathrm{Cr}(\mathrm{III})$ and $\mathrm{H}_{2} \mathrm{O}_{2}$. As to the dependency on the concentration of $\mathrm{OH}$, there seem to be two reaction pathways: the major one is inversely dependent on $[\mathrm{OH}]$, and the other independent of $[\mathrm{OH}]$ (insignificant). A general rate equation is written as

$$
\begin{gathered}
\mathrm{R}=-\mathrm{d}\left[\mathrm{Cr}_{\mathrm{n}}(\mathrm{III})\right] / \mathrm{dt}=\mathrm{nd} \mathrm{d}[\mathrm{Cr}(\mathrm{VI})] / \mathrm{dt}=\mathrm{k}\left[\mathrm{Cr}_{\mathrm{n}}(\mathrm{III})\right]\left[\mathrm{H}_{2} \mathrm{O}_{2}\right]\left(1 /[\mathrm{OH}]+\mathrm{k}^{\prime}\right) \\
=\mathrm{k}_{\mathrm{OH}}\left[\mathrm{Cr}_{\mathrm{n}}(\mathrm{III})\right]\left[\mathrm{H}_{2} \mathrm{O}_{2}\right] \\
=\mathrm{k}_{\mathrm{obs}}\left[\mathrm{Cr}_{\mathrm{n}}(\mathrm{III})\right]
\end{gathered}
$$

where $\mathrm{n}=1,2$ and 3 for monomer, dimer, and trimer, respectively. Examples of the plots of $\mathrm{k}_{\mathrm{obs}}$ vs. $\left[\mathrm{H}_{2} \mathrm{O}_{2}\right]$ are shown in Figure 4 for the monomer, dimer, and trimer, respectively. It can be seen that, at the same concentrations of $\mathrm{H}_{2} \mathrm{O}_{2}$ and $\mathrm{NaOH}$, the oxidation rate decreases in the order monomer $>$ dimer $>$ trimer $>$ higher oligomers. 

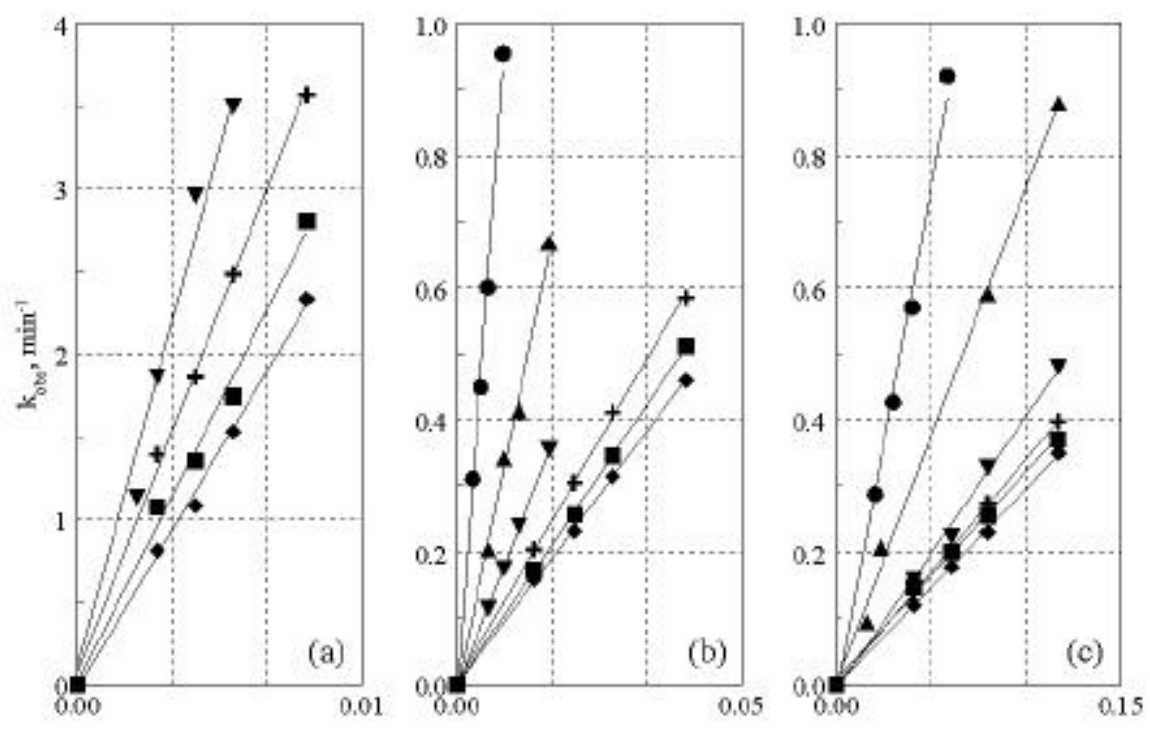

$\left[\mathrm{H}_{2} \mathrm{O}_{3}\right], \mathrm{M}$

Figure 4. The pseudo first-order rate constant, $\mathrm{k}_{\mathrm{obs}}$, as a function of $\left[\mathrm{H}_{2} \mathrm{O}_{2}\right]$ at constant $[\mathrm{OH}]$.

(a) monomer, (b) dimer, (c) trimer. Symbols: $[\mathrm{OH}]=0.100 \mathrm{M}(\mathrm{I}), 0.252 \mathrm{M}(\mathrm{s}), 0.504 \mathrm{M}(\mathrm{t})$, $0.756 \mathrm{M}(+), 1.00 \mathrm{M}(\mathrm{n}), 1.18 \mathrm{M}(\mathrm{u})$.

Values of the rate constant $\mathrm{k}$ [equation 1], calculated from these plots, are provided in Rao et al. [2002]. These values show that the oxidation rate decreases in the order monomer $>$ dimer $>$ trimer > higher oligomers. If $\left[\mathrm{H}_{2} \mathrm{O}_{2}\right]=0.01 \mathrm{M}$ and $[\mathrm{NaOH}]=1.0 \mathrm{M}$, the time required for $50 \%$ oxidation $\left(\mathrm{t}_{1 / 2}\right.$, in minutes) would be in the order monomer $(0.2)<\operatorname{dimer}(6)>\operatorname{trimer}(22)>$ unseparated/aged $\mathrm{Cr}$ (III) (410). In brief summary, our data indicate that, 1) $\mathrm{H}_{2} \mathrm{O}_{2}$ can oxidize $\mathrm{Cr}(\mathrm{III})$ to $\mathrm{Cr}(\mathrm{VI})$ in alkaline solutions; 2 ) the oxidation probably occurs through a ratedetermining step involving the breaking of the bridging bonds in the oligomers and the concomitant release of one hydroxyl group from the $\mathrm{Cr}$ (III) moiety upon the attack by $\mathrm{H}_{2} \mathrm{O}_{2}$; and 3 ) it is likely that more energy is required to break the bridging bonds in higher oligomers. Consequently, the redox reactivity of the $\mathrm{Cr}$ (III) species with $\mathrm{H}_{2} \mathrm{O}_{2}$ decreases as oligomerization proceeds.

Oxidation of $\mathrm{Cr}$ (III) by $\mathbf{S}_{\mathbf{2}} \mathrm{O}_{\mathbf{8}}$ in Alkaline Solutions. Oxidation of $\mathrm{Cr}$ (III) by persulfate follows a different kinetics mechanism [Friese et al. 2002b). This is most easily demonstrated by comparing Figure 5 with the results of $\mathrm{Cr}$ (III) oxidation by peroxide [Figure 4]. When [NaOH] $<1 \mathrm{M}$, the reaction rate is best described by multiple first-order processes. When $[\mathrm{NaOH}]>1 \mathrm{M}$, $\mathrm{Cr}$ (III) oxidation by persulfate is best described by a single first-order process; note that the linear dependence on oxidant concentration observed with peroxide is only observed with persulfate at very high concentrations of $\mathrm{NaOH}$ (e.g., $\sim 5 \mathrm{M} \mathrm{NaOH})$. 


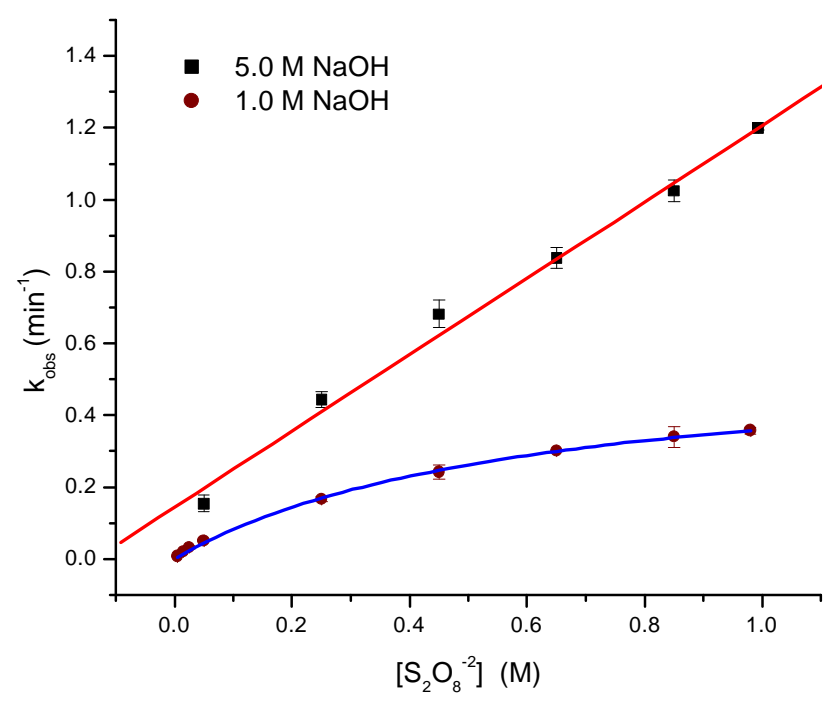

Figure 5. Observed rate constants for the oxidation of $\mathrm{Cr}(\mathrm{III})$ by persulfate in $\mathrm{NaOH}$. [Cr(III)] = $1 \times 10^{-4} \mathrm{M}, \mathrm{T}=22^{\circ} \mathrm{C}$. Note that, unlike oxidation by peroxide, the observed reaction rates are only linear with respect to persulfate concentration when $[\mathrm{NaOH}]$ is quite large.

Detailed investigations over wide ranges of conditions (e.g., [NaOH], [persulfate], and temperature) have revealed the following important conclusions: 1) There is a very rapid oxidation step probably involving the sulfate radical $\left(\mathrm{SO}_{4}^{-{ }^{-}}\right)$[Koltoff and Miller 1951]. Conditions that favor oxidation by the persulfate radical include $[\mathrm{NaOH}]<1 \mathrm{M}$ and temperatures elevated to at least $30^{\circ} \mathrm{C}$. 2) A second process in the oxidation of $\mathrm{Cr}$ (III) by persulfate follows Michelis-Menton-type kinetics, suggesting the formation of an intermediate species.

For oxidation with both peroxide and persulfate, there are two implications that are of great significance to the design of oxidative sludge washing to remove $\mathrm{Cr}$ : 1) any processes that can break down the oligomers will facilitate the oxidation, thus, the dissolution of $\mathrm{Cr}$; and 2) though the oxidation occurs in alkaline solutions, high concentrations of $\mathrm{NaOH}$ will slow the oxidation.

\section{End-User Connection: Tests Against Data on Washed Solids from High-Level Tanks}

Ideally, the fundamental data developed under this EMSP project need to be tested with welldesigned protocols of actual sludge washing. However, extensive studies with actual sludges are extremely expensive and beyond the scope of this EMSP funding. As a result, we decided to use the data that is available in technical reports from PNNL [Rapko et al. 1995; Lumetta et al. 1996, 1997] on the washing of Hanford tank sludges. Although these data do not cover a sufficiently wide range of hydroxide concentrations or rigidly controlled experimental conditions we desire, they do provide a limited data set to test the applicability of fundamental data developed under the current EMSP. 
In the study of the pretreatment of Hanford tank sludges supported by the TFA [Rapko et al. 1995; Lumetta et al. 1996, 1997], three washings were performed on sludges from 14 different Hanford tanks: 1) retrieval and dilute $\mathrm{NaOH}$ washes, 2) first caustic leach, and 3) second caustic leach. These sludges are representative of the four major chemical processing operations (REDOX, TBP, $\mathrm{BiPO}_{4}$, and PUREX) used at Hanford.

The comparison of the observed $\mathrm{Cr}$ concentrations in the three washes to the predicted $\mathrm{Cr}$ concentrations from our thermodynamic model are shown in Figure 6. The predicted concentrations are orders of magnitude lower than the observed for the first wash, fairly close to the observed for the second wash (about one order of magnitude lower for a few sludges), and in excellent agreement with the observed for the third wash. At present, the exact reason for the significant disagreement for the first wash is not known, but we surmise it may result from the presence of $\mathrm{Cr}(\mathrm{VI})$, other electrolytes (e.g., carbonate and phosphate) that were not included in the research investigations under the current EMSP project, and probably the leaching protocols. Nonetheless, The excellent agreement for the third wash (and, to less extent, the second) is very encouraging. If the effect of other electrolytes is significant, the extended studies proposed in this renewal will generate an improved thermodynamic model to account for the effects of these electrolytes. If the disagreement is due mainly to the leaching protocols, we will recommend modifications of the leaching protocol to the TFA investigators so that future leaching tests provide more meaningful and informative results. The interim thermodynamic parameters developed under the current program are being included in the TFA's Environmental Simulations Program for use by the site personnel. 


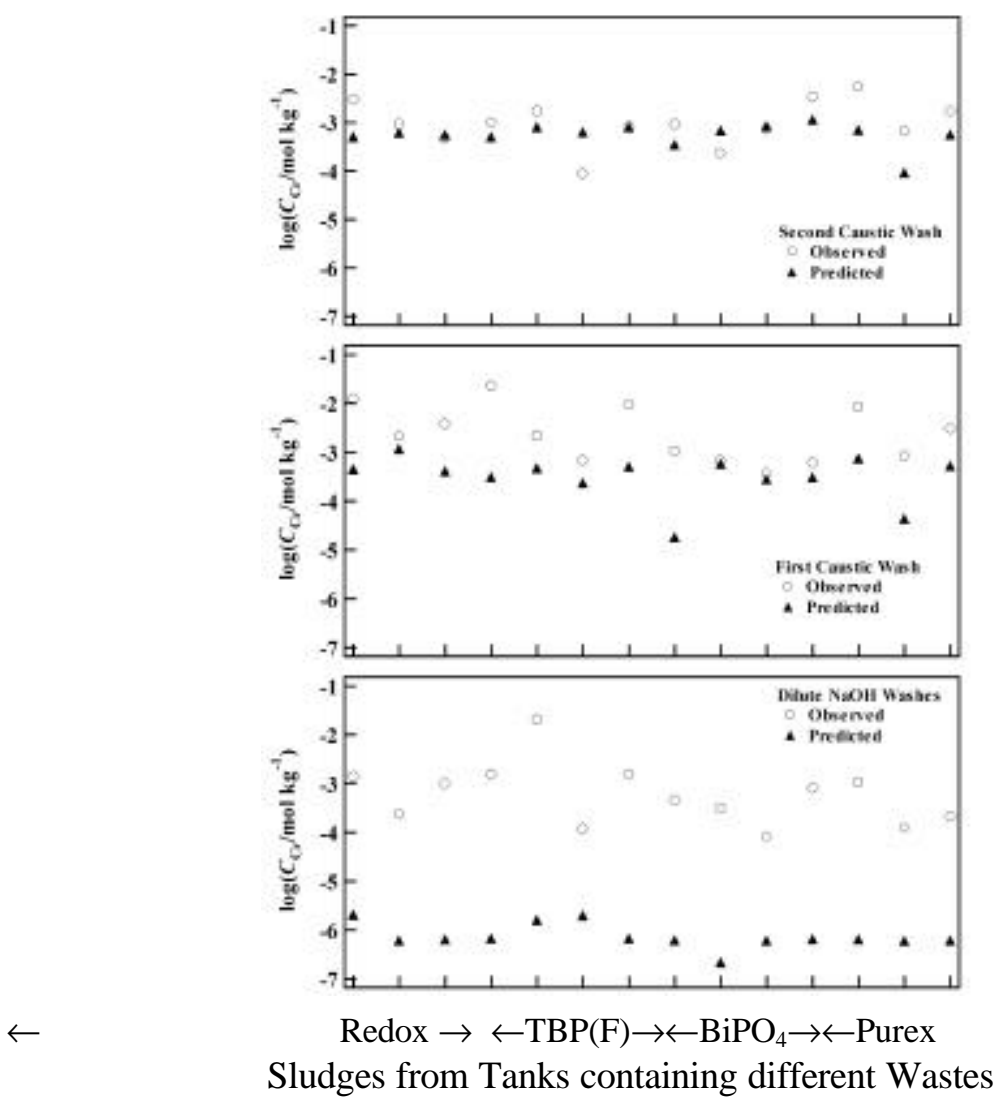

Figure 6. Predicted and observed chromium concentrations in sludge leachates (points on $x$-axis from left to right represent Hanford tanks S101, S104, S107, S111, BY104, BY108, BY110, T104, C107, BX107, B111, T111, C103, and AN104). Electrolytes in leachates vary from a mixture containing sodium, aluminum, hydroxide, nitrate, nitrite, phosphate, carbonate, and sulfate in various proportions to primarily $\mathrm{NaOH}$ (see Rai et al. 2002 for details).

\section{References Cited}

Rai D, NJ Hess, L Rao, Z Zhang, AR Felmy, DA Moore, SB Clark, GJ Lumetta. 2002. Thermodynamic Model for the Solubility of $\mathrm{Cr}(\mathrm{OH})_{3}(\mathrm{am})$ in Concentrated $\mathrm{NaOH}$ and NaOH$\mathrm{NaNO}_{3}$ Solutions. Journal of Solution Chemistry 31:343-367.

Rao L, Z Zhang, JI Friese, B Ritherdon, SB Clark, NJ Hess, and D Rai. 2002. Oligomerization of Chromium(III) and its Impact on the Oxidation of Chromium(III) by Hydrogen Peroxide in Alkaline Solutions. J. Chem. Soc., Dalton Trans. 2002(2): 267 - 274.

Friese JI, B Ritherdon, SB Clark, Z Zhang, L Rao, and D Rai. 2002a. Chromatographic Separation and Characterization of Hydrolyzed Cr(III) Species. Analytical Chemistry (In press). 
Friese JI, B Ritherdon, SB Clark, L Rao, and Z Zhang. 2002b. Oxidation of Cr(III) Oligomers by Persulfate Under Alkaline Conditions. To be submitted to Inorganic Chemistry.

Krot NN, FP Shilov, AM Fedoseev, NA Budantseva, MV Nikonov, MAB Yusov, AY Garnov, IA Charushnikova, VP Perminov, LN Astafurova, TS Lapitskaya, VI Makarenkov. 1999. Development of Alkaline Oxidative Dissolution Methods for Chromium(III) Compounds Present in Hanford Site Tank Sludges. PNNL-12209, UC-2000.

Koltoff IM and IK Miller. 1951. The Chemistry of Persulfate. I. The Kinetics and Mechanism of the Decomposition of the Persulfate Ion in Aqueous Medium. J. Am. Chem. Soc. 73:3055-3059.

Lumetta GJ, BM Rapko, MJ Wagner, J Liu, and YL Chen. 1996. Washing and Caustic Leaching of Hanford Tank Sludges: results of FY 1996 Studies. PNNL-11278, Rev. 1. Pacific Northwest National Laboratory, Richland, Washington, USA.

Lumetta GJ, IE Burgeson, MJ Wagner, J Liu, and YL Chen. 1997. Washing and Caustic Leaching of Hanford Tank Sludge: Results of FY 1997 Studies. PNNL-11636. Pacific Northwest National Laboratory, Richland, Washington, USA.

Rapko BM, GJ Lumetta, and JJ Wagner. 1995. Washing and Caustic Leaching of Hanford Tank Sludges: Results of FY 1995 Studies. PNNL-10712. Pacific Northwest National Laboratory, Richland, Washington, USA.

\section{Planned Activities}

Building on our research accomplishments to date, we are extending our current studies into three important areas: 1) the dissolution/precipitation of other important $\mathrm{Cr}$ solid phases, including $\mathrm{CrO}(\mathrm{OH})(\mathrm{s})$, and binary $\mathrm{Cr} / \mathrm{Fe}$ and $\mathrm{Cr} / \mathrm{Al}$ hydroxide solids; 2) the speciation of $\mathrm{Cr}(\mathrm{III})$ in the presence of other ligands (e.g., phosphate, carbonate) and the development of thermodynamic data for important $\mathrm{Cr}$ (III) solubility and complexation reactions; 3 ) the kinetics and mechanisms of the oxidation of $\mathrm{Cr}$ (III) by more oxidants, including $\mathrm{O}_{2}$ and ferrate. The data and model obtained in these studies will be tested with results from actual sludge washing and communicated with the end-users. These data will be incorporated into the Tanks Focus Area ESP model. 


\section{Information Access}

\section{Journal Articles}

Rai D, NJ Hess, L Rao, Z Zhang, AR Felmy, DA Moore, SB Clark, GJ Lumetta. 2002.

Thermodynamic Model for the Solubility of $\mathrm{Cr}(\mathrm{OH})_{3}(\mathrm{am})$ in Concentrated $\mathrm{NaOH}$ and $\mathrm{NaOH}-$

$\mathrm{NaNO}_{3}$ Solutions. Journal of Solution Chemistry 31: 343-367.

Rao L, Z Zhang, JI Friese, B Ritherdon, SB Clark, NJ Hess, and D Rai. 2002. Oligomerization of Chromium(III) and Its Impact on the Oxidation of Chromium(III) by Hydrogen Peroxide in Alkaline Solutions. J. Chem. Soc., Dalton Trans. 2002(2): 267 - 274.

Friese JI, B Ritherdon, SB Clark, Z Zhang, L Rao, and D Rai. 2002. Chromatographic Separation and Characterization of Hydrolyzed Cr(III) Species. Analytical Chemistry (In press).

Friese JI, B Ritherdon, SB Clark, L Rao, and Z Zhang. 2002. Oxidation of Cr(III) Oligomers by Persulfate Under Alkaline Conditions. To be submitted to Inorganic Chemistry.

\section{Technical Reports}

Rai D, L Rao, SB Clark, NJ Hess, and GJ Lumetta. 1999. Speciation, Dissolution, and Redox Reactions of Chromium Relevant to Pretreatment and Separation of High-Level Tank Wastes. In: Science to Support DOE Site Cleanup: The Pacific Northwest National Laboratory Science Program Awards. PNNL- 12208, Pacific Northwest National Laboratory, Richland, WA, pp. 1.61-1.86.

Rai D, L Rao, SB Clark, NJ Hess, and GJ Lumetta. 2000. Speciation, Dissolution, and Redox Reactions of Chromium Relevant to Pretreatment and Separation of High-Level Tank Wastes. In: Science to Support DOE Site Cleanup: The Pacific Northwest National Laboratory Science Program Awards. PNNL- 13262, Pacific Northwest National Laboratory, Richland, WA, pp. 1.15-1.17.

Rai D, L Rao, SB Clark, and NJ Hess. March 2000. Speciation, Dissolution, and Redox Reactions of Chromium Relevant to Pretreatment and Separation of High-Level Tank Wastes. Project Summary submitted to EMSP. 


\section{Presentations}

Rao L, D Rai, SB Clark, AR Felmy, NJ Hess, Z Zhang, and B Ritherdon. 1999. Speciation, Dissolution, and Redox Reactions of Cr(III) in Alkaline Solutions. A presentation at the 218th ACS National Meeting, New Orleans, Louisiana, August 1999.

Rao L, D Rai, SB Clark, Z Zhang, NJ Hess, B Ritherdon, and J Friese. 2000. Dissolution of $\mathrm{Cr}(\mathrm{OH})_{3}(\mathrm{am}) / \mathrm{Cr}_{2} \mathrm{O}_{3}(\mathrm{c})$ and Oxidation of $\mathrm{Cr}(\mathrm{III})$ in Alkaline Solutions. A presentation at the 219th ACS National Meeting, San Francisco, California, March 2000.

Friese J, B Ritherdon, O Gerasimov, S Lymar, J Hurst, Z Zhang, L Rao, D Rai, and SB Clark. 2000. Oxidation of Trivalent Cr Using Oxidants Relevant to High-Level Radioactive Waste. A presentation at the 219th ACS National Meeting, San Francisco, California, March 2000.

Rai D, L Rao, SB Clark, NJ Hess, and AR Felmy. 2000. Solubility of Cr(III) Compounds and Their Redox Transformation Reactions: Application to Pretreatment of High-Level Waste Sludges. An oral presentation at the EMSP workshop, Atlanta, Georgia, April 2000.

Rai D, L Rao, SB Clark, NJ Hess, and AR Felmy. 2000. Speciation, Dissolution, and Redox Reactions of Chromium Relevant to Pretreatment and Separation of High-Level Tank Wastes. Poster presentation at the EMSP workshop, Atlanta, Georgia, April 2000.

Friese J, B Ritherdon, SB Clark, L Rao, and Z Zhang. 2000. Removing Chromium from HighLevel Radioactive Waste Streams: Speciation and Reactivity of $\mathrm{Cr}$ (III) Oligomers Under Highly Alkaline Conditions. A presentation at the 221th ACS National Meeting, San Diego, California, April 2001. 